\title{
Conference proceedings of the Transcultural Special Interest Group
}

\author{
Deenesh Khoosal and Parimala Moodley
}

A one-day symposium was held at the Royal College of Psychiatrists on 4 October 1994 by the Transcultural Special Interest Group (TSIG) entitled The Practice of Psychiatry in a Multi-Cultural Context'. Speakers included Yvonne Christie of the Reglonal Race Programme for the NHS Mental Health Task Force, Drs Suman Fernando, Sashidharan, Ndegwa, Nasirullah, and Mahadeshwar.

One of the central themes was the certain knowledge that there was a great deal of expertise within the black and ethnic minority communities outside of the statutory services. These groups wanted to participate in the process which determined service provision but too often they were neither consulted nor empowered to make their views known.

Regular ongoing dialogue with black and ethnic minority groups, communities, and organisations, would serve to identify problems in present service provision and go a long way to meeting unmet needs. Employment of bi-lingual staff was highly commended in preference to an interpreter service. It also seems clear that the establishment of separate services or facilities needed to be considered for certain groups, for example women. The effect of racism on people's lives needed to be acknowledged and worked with. There is a clear need for training about race and culture in all professional programmes.

The home treatment model in inner-city Birmingham seemed to work for the community because the legitimate concerns of managers, clinicians, voluntary groups and consumers had sensibly been taken into account.

Traditional psychotherapy did not seem to be as well tailored for patients from black or ethnic minority groups. The cultural expectations of patients with learning disability, their relattves and carers, need to be taken into account when planning care programmes if these are to be meaningful and effective.

We strongly believe that it is possible to practise psychiatry in a multi-cultural context, provided that the therapists are culturally and racially sensitive, and that there is adequate consultation and liaison, not only with users of the service but also with their families and the wide range of organisations in the community.

Any Member, Fellow or Inceptor of the College wishing to join this Special Interest Group, should contact Mrs Jean Wales for further information.

Deenesh Khoosal, Secretary; and Parimala Moodley, Chairperson, Transcultural Special Interest Group, Royal College of Psychiatrists 